\title{
Disability and Recovery of Independent Function in Obstructive Lung Disease: The Cardiovascular Health Study
}

\author{
Vincent S. Fan ${ }^{\mathrm{a}, \mathrm{b}}$ Emily R. Locke ${ }^{\mathrm{a}}$ Paula Diehr ${ }^{\mathrm{c}}$ Anthony Wilsdon ${ }^{\mathrm{c}}$ \\ Paul Enright ${ }^{\mathrm{e}}$ Sachin Yende ${ }^{f}$ Mark Avdalovic $^{g}$ Graham Barr $^{\mathrm{h}}$ \\ Vishesh K. Kapur $^{\mathrm{b}}$ Rachel Thomas $^{\mathrm{a}}$ Jerry A. Krishnan ${ }^{j}$ Gina Lovasi $^{\mathrm{i}}$ \\ Stephen Thielke ${ }^{d}$
}

${ }^{a}$ Health Services Research and Development, Department of Veterans Affairs, and Departments of ${ }^{\mathrm{b}}$ Medicine and 'Biostatistics, and dPsychiatry and Behavioral Sciences, University of Washington, Seattle, Wash., e University of Arizona, Tucson, Ariz., fDepartment of Critical Care Medicine, University of Pittsburgh, Pittsburgh, Pa., 9 Division of Pulmonary and Critical Care, University of California-Davis, Sacramento, Calif., ${ }^{\mathrm{h}}$ Columbia University Medical Center, and 'Department of Epidemiology, Columbia University, New York, N.Y., and 'University of Illinois Hospital and Health Sciences System, Chicago, III., USA

\section{Key Words}

Chronic airflow obstruction · Activities of daily living ·

Disability

\begin{abstract}
Background: Chronic obstructive lung disease frequently leads to disability. Older patients may experience transitions between states of disability and independence over time. Objective: To identify factors associated with transition between states of disability and independent function in obstructive lung disease. Methods: We analyzed data on 4,394 participants in the Cardiovascular Health Study who completed prebronchodilator spirometry. We calculated the 1 -year probability of developing and resolving impairment in $\geq 1$ instrumental activity of daily living (IADL) or $\geq 1$ activity of daily living ( $A D L)$ using transition probability analysis. We identified factors associated with resolving disability using relative risk (RR) regression. Results: The prevalence of IADL impairment was higher with moderate (23.9\%) and severe
\end{abstract}

(36.9\%) airflow obstruction compared to normal spirometry (22.5\%; $p<0.001)$. Among participants with severe airflow obstruction, $23.5 \%$ recovered independence in IADLs and $40.5 \%$ recovered independence in $A D L s$. In the adjusted analyses, airflow obstruction predicted the development of IADL, but not ADL impairment. Participants with severe airflow obstruction were less likely to resolve IADL impairment [RR 0.67 and $95 \%$ confidence interval $(\mathrm{Cl}) 0.49-0.94]$. Compared to the most active individuals (i.e. who walked $\geq 28$ blocks per week), walking less was associated with a decreased likelihood of resolving IADL impairment (7-27 blocks: RR 0.81 and 95\% Cl 0.69-0.86 and <7 blocks: RR 0.73 and 95\% Cl 0.610.86). Increased strength (RR 1.16 and $95 \% \mathrm{Cl} 1.05-1.29$ ) was associated with resolving IADL impairment. Conclusions: Disability is common in older people, especially in those with severe airflow obstruction. Increased physical activity and muscle strength are associated with recovery. Research is needed on interventions to improve these factors among patients with obstructive lung disease and disability.

(c) 2014 S. Karger AG, Base

Vincent S. Fan, MD, MPH

Health Services Research and Development, VA Puget Sound Health Care System 1660 S. Columbian Way, S-152

Seattle, WA 98108 (USA)

E-Mail Vincent.fan@va.gov 


\section{Introduction}

Chronic obstructive pulmonary disease (COPD) is a progressive disease recognized as a major cause of disability worldwide [1]. Understanding the role of functional limitations and disability in chronic illness is a key priority for research recommended by the Institute of Medicine [2], and respiratory impairment is an important factor contributing to functional limitations [3-7]. Once people with obstructive lung disease develop a disability, how likely they are to remain disabled or recover independence over time is not well understood.

To better describe the longitudinal trajectory of function limitation in obstructive lung disease, several studies have examined changes in health status over time. The findings are that, on average, health-related quality-oflife [8-11] and functional performance [12] worsen over time, and several authors have suggested that the course of COPD is a spiral of decline characterized by progressively worsening physical functioning $[13,14]$.

Data from other populations suggest, however, that disability is a dynamic condition and that chronically ill patients may often experience a transition between states of disability and independence over time [15]. Furthermore, patients with new impairments in the activities of daily living (ADL) often recover independent function [16]. A longitudinal Dutch study found that in chronic lung disease, patients with self-reported asthma or COPD had several different disability trajectories, including recovery in function [17].

Disability in obstructive lung disease may therefore be more dynamic than originally thought, and an understanding of the potentially reversible factors associated with recovery of independent function would enable the development or implementation of programs to improve functional status for patients. Using transition probability analysis, the aims of this study were to estimate the probability of a transition between disability and no disability over time in a larger cohort of older individuals with and without lung disease. We then sought to identify the factors that are associated with the development and recovery from disability, and whether these differed between patients with and without lung disease.

\section{Material and Methods}

\section{Participants}

The Cardiovascular Health Study (CHS) was a populationbased, longitudinal study of coronary heart disease and stroke [18]. Community-dwelling adults $\geq 65$ years were identified through

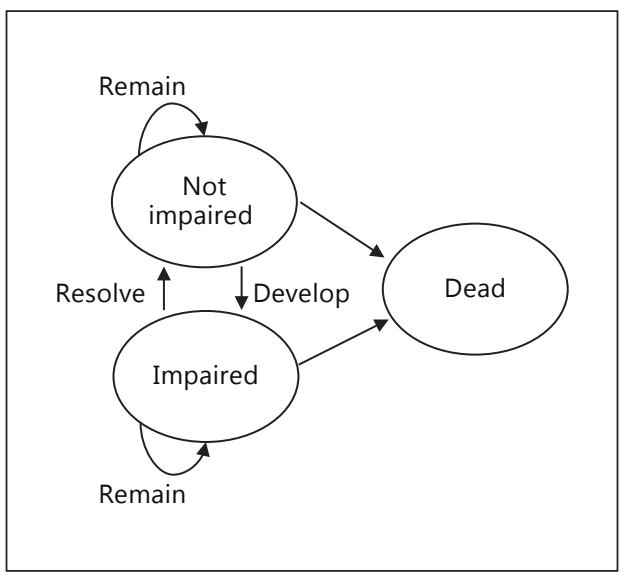

Fig. 1. Transition probability model with states of impairment.

Medicare eligibility lists in four communities in the USA, and were excluded if they needed a wheelchair, received hospice care, radiation treatment or chemotherapy. In 1989-1990 (first cohort), 5,201 participants were recruited and in 1992-1993 (second cohort), 687 African American participants were recruited. Sociodemographic and health data were obtained from personal interviews, medical record review and clinical examination. Subjects participated in yearly study visits which included assessments of disability. Mortality was ascertained by surveillance and semiannual contact with participants and their families.

Spirometry was performed in 1989-1990 in the first cohort, and in 1993-1994 and 1996-1997 in both cohorts. The first year in which spirometry was conducted was taken as the index visit. Participants provided their informed consent and institutional review board approval was obtained.

\section{Identification of Participants with Airflow Obstruction}

The CHS pulmonary function testing procedures are detailed elsewhere [19]. We included spirometry values meeting the American Thoracic Society (ATS) 1994 recommendations (grades $\mathrm{A}-\mathrm{C})$, and excluded unreasonably high or low values $\left(\mathrm{FEV}_{1}>5.5\right.$ and $<0.5$; FVC $>6.0$ and $<0.5$ ) [19].

Using reference equations from the National Health and Nutrition Examination Survey III [20], airflow obstruction was defined as $\mathrm{FEV}_{1} / \mathrm{FVC}<$ lower limit of normal (LLN), and severity of obstruction was categorized as mild $\left(80 \%<\mathrm{FEV}_{1}\right)$, moderate $(50 \%<$ $\left.\mathrm{FEV}_{1} \leq 80 \%\right)$ or severe $\left(\mathrm{FEV}_{1}<50 \%\right.$ predicted $)$.

Among patients without obstruction, possible restrictive lung disease was defined as having an FVC $<$ LLN. Restriction may be due to several different etiologies including obesity, muscular weakness and (rarely) interstitial lung disease [21]. However, restrictive lung disease cannot be definitively diagnosed with spirometry alone and requires lung volumes, which were not performed in the CHS, to confirm the diagnosis. Many individuals with a reduced $\mathrm{FVC}$ and $\mathrm{FEV}_{1}$ but a normal ratio have airways disease [22], but they are just as likely to develop obstruction or restriction over time [23]. Because of the inaccuracy in correctly categorizing patients in the group of possible restriction, we limited the analyses to those with either normal spirometry or airflow obstruction. 
Fig. 2. Participants included in the anal-

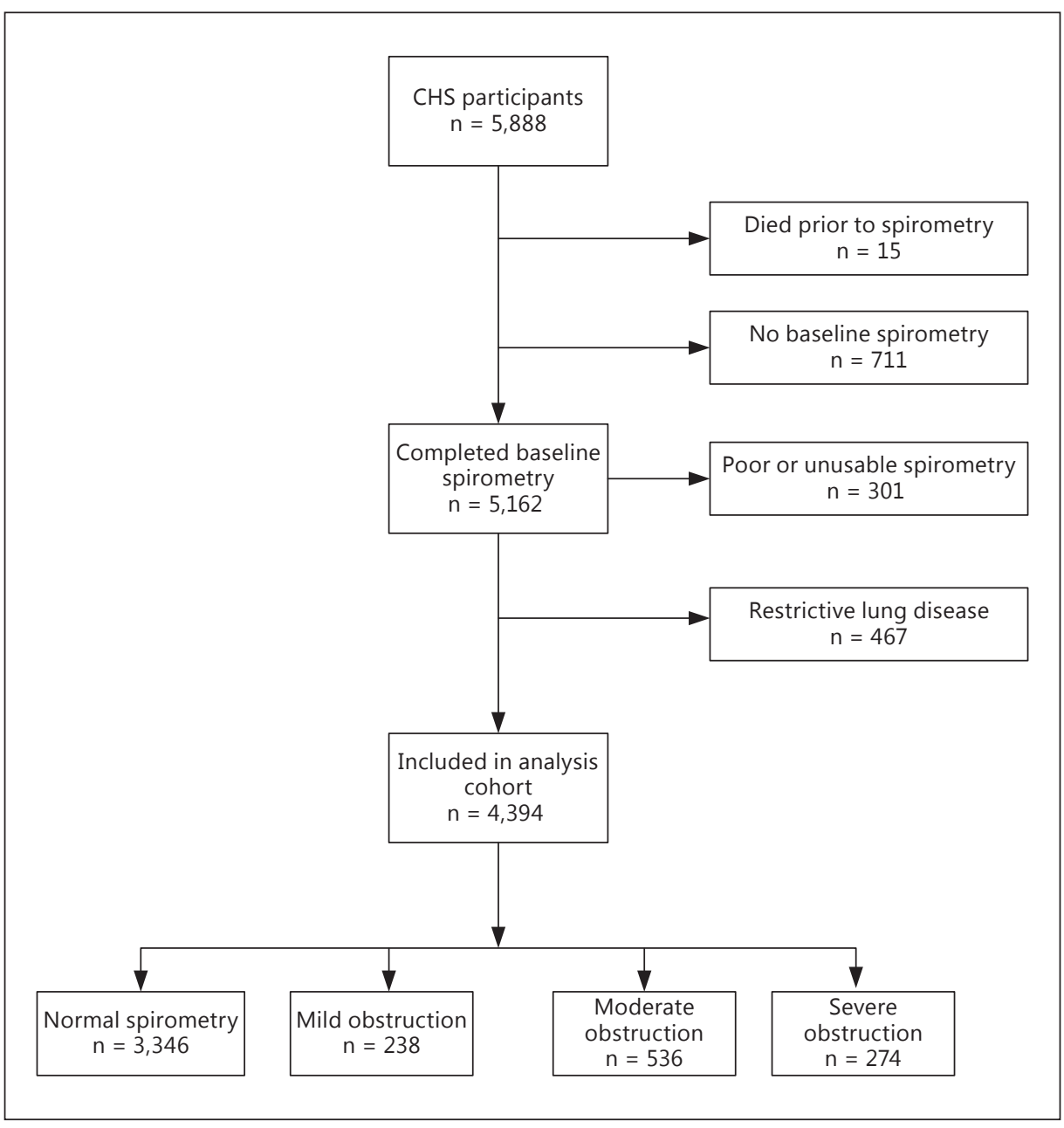
ysis cohort.

\section{Disability}

Disability was assessed with both the instrumental activities of daily living (IADL) and ADL. IADLs were defined as a self-reported difficulty or inability to perform any of the following: heavy or light housework, shopping, preparing meals, paying bills or using the phone. ADLs were defined as difficulty or an inability with walking around the home, getting out of bed, eating, dressing, bathing or using the toilet. Only very severe airflow obstruction is likely to result in difficulties with ADLs such as using the toilet, bathing or eating, so we focused the primary analysis on the development of and recovery from IADL impairment.

\section{Covariates}

We assessed variables potentially associated with development or resolution of disability. We included comorbidities from the Charlson Index [24], available in the CHS to construct a comorbidity count $(0,1$ or $\geq 2)$ of 10 conditions (kidney disease, liver disease, leukemia, lymphoma, cancer, stroke/TIA, claudication, congestive heart failure, myocardial infarction and diabetes). Selfreported physician diagnosis of asthma was included as a separate variable. A score of $\geq 10$ on the 10-item CES-D (Center for Epidemiologic Studies Short Depression Scale; range 0-30), was consid- ered depressed [25]. A score of $<80$ on the 3MS (Modified Mini Mental State) exam, on a 100-point scale, was defined as a cognitive impairment [26]. Hand-grip strength (in kilograms) was measured using a hand-held Jamar dynamometer. Physical activity was measured as the number of self-reported blocks walked during the previous week. Severity of disability was measured as the total number of self-reported impairments. The ATS-DLD-78 scale was used to measure dyspnea (range 0-5) [27].

If the patient was still alive, we imputed missing values of disability status by interpolation between two known values where possible. Otherwise, the missing value was imputed from the person's last available value, self-rated health and eventual date of death [28]. Over the 6-year study period, $8 \%$ of the IADL values were imputed.

\section{Analysis}

Transition Probabilities

We used transition probability analysis to estimate the transition probabilities between 3 states for each category of lung disease, based on the 2 time periods after baseline spirometry was performed [29]. We defined 3 possible states: (1) alive without disability, (2) alive and disabled and (3) dead (fig. 1). 
Table 1. Baseline characteristics of participants

\begin{tabular}{|c|c|c|c|}
\hline Characteristic & $\begin{array}{l}\text { Normal lung } \\
\text { function } \\
(\mathrm{n}=3,346)\end{array}$ & $\begin{array}{l}\text { Obstructed } \\
(\mathrm{n}=1,048)\end{array}$ & $\begin{array}{l}\mathrm{p} \\
\text { value }\end{array}$ \\
\hline Age, years & $72.7 \pm 5.5$ & $72.7 \pm 5.4$ & 0.786 \\
\hline Male gender & 38.9 & 50.1 & $<0.001$ \\
\hline Race & & & 0.552 \\
\hline White & 88.1 & 87.5 & \\
\hline African American & 11.9 & 12.6 & \\
\hline Education & & & $<0.001$ \\
\hline$\leq 8$ th grade & 12.8 & 16.9 & \\
\hline $9-11$ th grade & 12.7 & 15.5 & \\
\hline 12 th grade & 28.2 & 27.0 & \\
\hline$>12$ th grade & 46.4 & 40.6 & \\
\hline Married & 67.9 & 65.8 & 0.218 \\
\hline Smoking status & & & $<0.001$ \\
\hline Never & 52.9 & 22.9 & \\
\hline Past & 40.1 & 53.3 & \\
\hline Current & 7.0 & 23.9 & \\
\hline Body mass index & & & $<0.001$ \\
\hline$\leq 25.0$ & 37.4 & 46.8 & \\
\hline $25.0-29.9$ & 43.9 & 37.5 & \\
\hline$\geq 30.0$ & 18.6 & 15.7 & \\
\hline ATS dyspnea scale & & & $<0.001$ \\
\hline 0 & 67.7 & 48.8 & \\
\hline 1 & 19.3 & 25.1 & \\
\hline 2 & 4.1 & 7.8 & \\
\hline 3 & 2.7 & 5.8 & \\
\hline 4 & 4.0 & 7.8 & \\
\hline 5 & 2.3 & 4.6 & \\
\hline Asthma & 3.7 & 13.8 & $<0.001$ \\
\hline Depression & 12.1 & 13.2 & 0.321 \\
\hline Chronic conditions $^{\mathrm{b}}$ & & & 0.001 \\
\hline 0 & 71.6 & 65.8 & \\
\hline 1 & 21.5 & 24.6 & \\
\hline$\geq 2$ & 6.9 & 9.5 & \\
\hline Hand grip strength $^{c}$ & & & 0.003 \\
\hline$<20 \mathrm{~kg}$ & 18.9 & 15.3 & \\
\hline $20-39 \mathrm{~kg}$ & 64.7 & 64.5 & \\
\hline$\geq 40 \mathrm{~kg}$ & 16.4 & 20.2 & \\
\hline Cognitive impairment ${ }^{c}$ & 7.8 & 10.2 & 0.016 \\
\hline \multicolumn{4}{|l|}{ Blocks walked in a week } \\
\hline$<7$ & 24.7 & 29.9 & 0.001 \\
\hline $7-27$ & 34.9 & 35.4 & \\
\hline$\geq 28$ & 40.4 & 34.7 & \\
\hline Hospitalized in the last year & 8.7 & 9.1 & 0.713 \\
\hline $\mathrm{FEV}_{1}$, liters & $2.27 \pm 0.59$ & $1.57 \pm 0.59$ & $<0.001$ \\
\hline $\mathrm{FEV}_{1} \%$ predicted & $97.9 \pm 14.5$ & $64.7 \pm 20.4$ & $<0.001$ \\
\hline FVC, liters & $3.08 \pm 0.82$ & $2.81 \pm 0.89$ & $<0.001$ \\
\hline FVC $\%$ predicted & $98.7 \pm 13.4$ & $85.6 \pm 21.8$ & $<0.001$ \\
\hline $\mathrm{FEV}_{1} / \mathrm{FVC}$ ratio & $0.74 \pm 0.05$ & $0.55 \pm 0.09$ & $<0.001$ \\
\hline
\end{tabular}

All values are $\%$ or mean \pm SD. Percentages may not sum to 100 due to rounding. ${ }^{\text {a }} 0=$ No shortness of breath, $1=$ troubled by shortness of breath when hurrying or walking up a slight hill, 2 = walk slower than people your age, $3=$ have to stop walking at own pace, $4=$ have to stop after walking 100 yards, $5=$ too breathless to leave the house or breathless on dressing or undressing. ${ }^{\mathrm{b}}$ These include myocardial infarction, congestive heart failure, claudication, stroke and/or transient ischemic attack, diabetes, kidney disease, liver disease, lymphoma, leukemia and cancer. ${ }^{c}>5 \%$ missing information.
1-Year Risk of Developing and Resolving Disability

We focused our regression analysis on the transitions between disabled and nondisabled states. We used relative risk (RR) regression with generalized linear models, employing Poisson regression with robust error estimates to estimate the risk of developing or resolving $\geq 1$ disabilities over the next year [30]. For the analysis, we included all 1-year intervals following the administration of spirometry; as most participants in the first cohort had undergone spirometry on two occasions, they contributed two sets of interval data to the transition probability analysis. We did not use logistic regression because the odds ratio (OR) can overestimate the $R R$ in outcomes with $>10 \%$ probability.

Models were adjusted for baseline factors potentially associated with disability: age, gender, marital status, smoking status, comorbidities, asthma and strength, and also the factors measured yearly: hospitalization in the last year, severity of disability, depression, cognitive impairment and blocks walked in the last week. For variables that were collected yearly, the transition analysis included the value of the variable at the start of the 1-year transition interval. We determined whether the factors associated with resolving IADL or ADL impairment differed between participants with and without airflow obstruction with interaction terms to assess for effect modification.

\section{Results}

Of the 4,861 participants with usable spirometry, we included 1,048 with airflow obstruction and 3,346 with normal spirometry (fig. 2). Those with airflow obstruction were more likely to be male, to have smoked and be more dyspneic than those with normal lung function (table 1). They were also more likely to have cognitive impairment, have walked fewer blocks and have better grip strength than participants with normal lung function.

\section{Prevalence of Disability at Baseline}

IADL impairment was more frequent with obstruction than with normal lung function (27.2 vs. $22.5 \%$, p $<0.001$; table 2). Difficulty performing heavy housework was also more common with obstruction than with normal lung function ( $\mathrm{p}=0.007)$ and there were no significant differences in other impairments. The prevalence of any baseline IADL disability was higher with severe airflow obstruction $(36.9 \%)$ compared to moderate $(23.9 \%)$ and mild obstruction $(23.5 \%)$ or normal spirometry $(22.5 \%$; $\mathrm{p}<0.001)$. ADL impairments did not differ between subjects with airflow obstruction and those with normal lung function (table 2).

\section{Transition Probabilities}

A total of 6,987 1-year transition intervals were examined for this analysis. Of these, 5,410 subjects (77.4\%) 
Table 2. Baseline prevalence of ADL and IADL impairment

\begin{tabular}{|c|c|c|c|c|c|}
\hline & \multicolumn{2}{|c|}{ Normal lung function $(\mathrm{n}=3,346)$} & \multicolumn{2}{|c|}{ Obstructed $(\mathrm{n}=1,048)$} & \multirow[t]{2}{*}{$\mathrm{p}$ value } \\
\hline & $\mathrm{n}$ & $\%$ & $\mathrm{n}$ & $\%$ & \\
\hline$\geq 1$ ADL impairment & 232 & 6.9 & 79 & 7.5 & 0.505 \\
\hline \multicolumn{6}{|l|}{ Difficulty performing individual ADLs ${ }^{\mathrm{a}}$} \\
\hline Walking around the home & 89 & 2.7 & 28 & 2.7 & 0.953 \\
\hline Getting out of bed & 158 & 4.8 & 48 & 4.7 & 0.890 \\
\hline Eating & 11 & 0.3 & 3 & 0.5 & 0.830 \\
\hline Dressing & 25 & 0.8 & 9 & 0.9 & 0.721 \\
\hline Bathing & 42 & 1.3 & 20 & 1.9 & 0.119 \\
\hline Using the toilet & 10 & 0.3 & 7 & 0.7 & 0.093 \\
\hline$\geq 1$ IADL impairment & 754 & 22.5 & 285 & 27.2 & 0.002 \\
\hline \multicolumn{6}{|l|}{ Difficulty performing individual IADLs ${ }^{\mathrm{a}}$} \\
\hline Heavy housework & 694 & 21.2 & 259 & 25.2 & 0.007 \\
\hline Light housework & 53 & 1.6 & 24 & 2.3 & 0.131 \\
\hline Shopping & 131 & 3.9 & 46 & 4.4 & 0.492 \\
\hline Preparing meals & 46 & 1.4 & 20 & 1.9 & 0.214 \\
\hline Paying bills & 26 & 0.8 & 8 & 0.8 & 0.967 \\
\hline Using the phone & 51 & 1.5 & 24 & 2.3 & 0.095 \\
\hline
\end{tabular}

a Due to reports of multiple impairments within individuals, the prevalence of the individual impairments do not sum to the overall prevalence.

Table 3. Probability of transitioning between states of impairment in ADLs and IADLs by baseline lung function

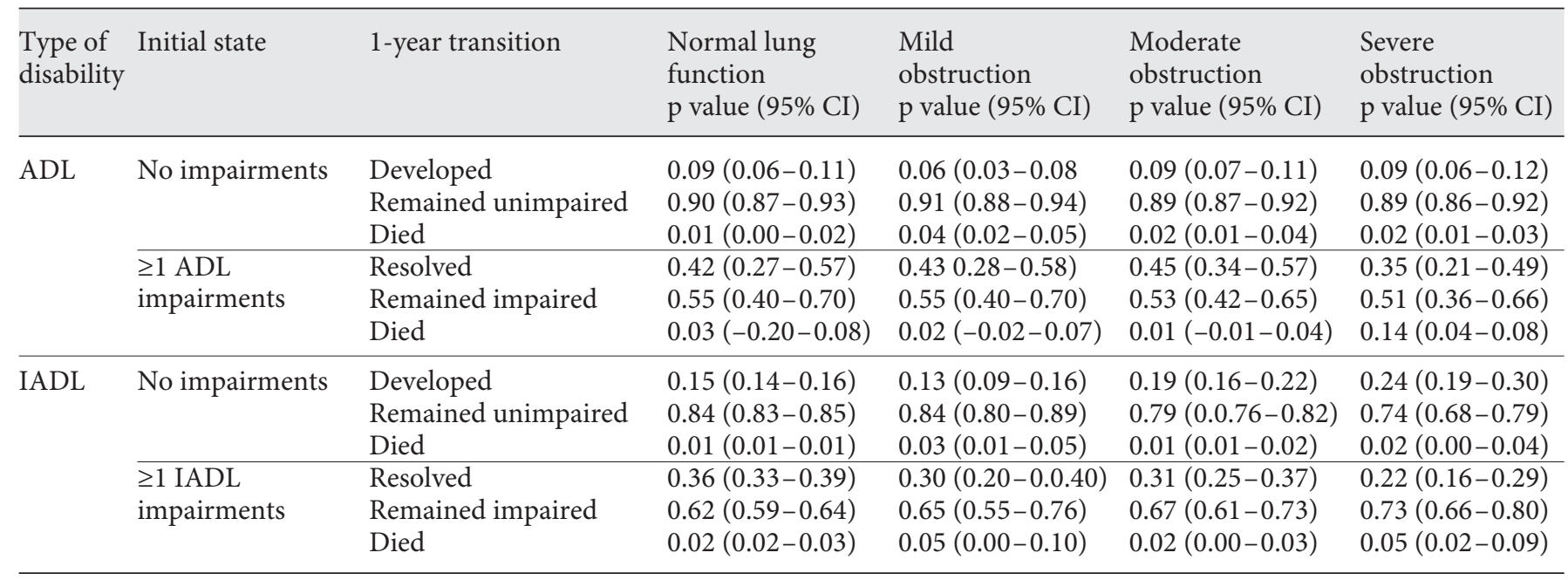

began with no IADL impairment, 6,396 (91.5\%) with no ADL impairment, 1,577 (22.6\%) had at least 1 IADL impairment and $591(8.5 \%)$ had at least 1 ADL impairment. The probability of developing impairment in IADL over a 1-year period was highest for those with severe obstruction $(\mathrm{p}=0.24)$ and lowest for those with normal lung function $(\mathrm{p}=0.15)$ or mild obstruction $(\mathrm{p}=0.13$; table 3$)$. In a large proportion $(30 \%)$ of participants with mild obstruction, IADL impairments had resolved within the next year, and even among those with severe obstruction, these impairments had resolved a year later. 
Table 4. RR regression to predict developing and resolving IADL impairment over 1 year

\begin{tabular}{|c|c|c|c|c|}
\hline & \multicolumn{2}{|c|}{ Developing $\geq 1$ IADL impairment } & \multicolumn{2}{|c|}{ Resolving $\geq 1$ IADL impairment } \\
\hline & $\mathrm{RR}$ & $95 \% \mathrm{CI}$ & $\mathrm{RR}$ & $95 \% \mathrm{CI}$ \\
\hline Age & 1.05 & $1.03-1.06$ & 0.99 & $0.98-1.00$ \\
\hline Male gender & 0.98 & $0.80-1.21$ & 0.97 & $0.77-1.20$ \\
\hline Unmarried & 1.12 & $0.97-1.29$ & 1.03 & $0.89-1.20$ \\
\hline \multicolumn{5}{|l|}{ Smoking status } \\
\hline Never & Ref. & - & Ref. & - \\
\hline Previous & 1.18 & $1.02-1.37$ & 0.94 & $0.81-1.09$ \\
\hline Current & 1.10 & $0.87-1.39$ & 1.16 & $0.91-1.48$ \\
\hline Depression & 1.51 & $1.27-1.79$ & 0.83 & $0.69-1.00$ \\
\hline \multicolumn{5}{|l|}{ Comorbidity } \\
\hline 0 & Ref. & - & Ref. & - \\
\hline 1 & 1.40 & $1.21-1.63$ & 0.87 & $0.74-1.02$ \\
\hline$\geq 2$ & 1.82 & $1.50-2.22$ & 0.57 & $0.43-0.75$ \\
\hline Asthma & 1.29 & $0.99-1.66$ & 0.86 & $0.61-1.21$ \\
\hline Cognitive impairment & 1.04 & $0.83-1.30$ & 0.89 & $0.59-1.32$ \\
\hline Grip strength, per 10 -unit increase ${ }^{\mathrm{a}}$ & 0.82 & $0.74-0.91$ & 1.16 & $1.05-1.29$ \\
\hline \multicolumn{5}{|l|}{ Blocks walked } \\
\hline$<7$ & 1.66 & $1.41-1.95$ & 0.73 & $0.61-0.86$ \\
\hline $7-27$ & 1.35 & $1.16-1.57$ & 0.81 & $0.69-0.95$ \\
\hline$\geq 28$ & Ref. & - & Ref. & - \\
\hline Hospitalized in the last year & 1.25 & $1.03-1.53$ & 0.92 & $0.74-1.14$ \\
\hline Severity of IADL impairment ${ }^{\mathrm{b}}$ & NA & - & 0.64 & $0.53-0.78$ \\
\hline \multicolumn{5}{|l|}{ Lung function } \\
\hline Normal & Ref. & - & Ref. & - \\
\hline Mild obstruction & 0.86 & $0.64-1.15$ & 0.97 & $0.68-1.36$ \\
\hline Moderate obstruction & 1.18 & $0.98-1.42$ & 0.97 & $0.79-1.21$ \\
\hline Severe obstruction & 1.44 & $1.11-1.87$ & 0.67 & $0.49-0.94$ \\
\hline
\end{tabular}

${ }^{a}$ For example, comparing a participant with a measured grip strength of $50 \mathrm{~kg}$ to an individual with a measured grip strength of $60 \mathrm{~kg}$. ${ }^{\mathrm{b}}$ This refers to the total number of impairments reported during the preceding year.

The probability of developing ADL impairment during 1-year of follow-up varied from 0.06 to 0.09 . Among those with ADL impairments, these impairments were resolved in $35-45 \%$ over the next year, including in 35\% of those with severe obstruction.

\section{Predictors of Developing and Resolving Disability over 1 Year}

After adjustment for baseline demographic characteristics and other comorbidities, severe airflow obstruction was associated with the development of IADL impairment over 1 year, with a RR of 1.44 [95\% confidence interval (CI) 1.11-1.87] compared to with normal lung function (table 4). Recent hospitalization also increased the risk of developing impaired IADL. Better grip strength and more blocks walked in a week were associated with a reduced risk of developing IADL impairment.
In a model to predict resolution of IADL impairment over the following year, participants with severe obstruction were less likely to resolve their disability than those with normal lung function (RR 0.67 and 95\% CI 0.490.94 ). Independent of lung function, we found that increasing grip strength (RR 1.16 and 95\% CI 1.05-1.29) was associated with resolving IADL disability. In addition, compared to those whose baseline physical activity was walking $\geq 28$ blocks per week, those who walked 7-27 blocks (RR 0.81 and 95\% CI 0.69-0.95) or $<7$ blocks (RR 0.73 and $95 \%$ CI $0.61-0.86)$ were less likely to resolve IADL impairment (table 4).

To determine whether the impact of potentially reversible factors such as a better grip strength or the number of blocks walked on resolving IADL impairment differed between those with airflow obstruction and those with normal spirometry, we assessed for effect modifica- 
Table 5. RR regression to predict developing and resolving ADL impairment over 1 year

\begin{tabular}{|c|c|c|c|c|}
\hline & \multicolumn{2}{|c|}{ Developing $\geq 1$ ADL impairment } & \multicolumn{2}{|c|}{ Resolving $\geq 1$ ADL impairment } \\
\hline & $\mathrm{RR}$ & $95 \% \mathrm{CI}$ & $\mathrm{RR}$ risk & $95 \% \mathrm{CI}$ \\
\hline Age & 1.05 & $1.03-1.06$ & 0.97 & $0.95-0.99$ \\
\hline Male gender & 1.10 & $0.85-1.41$ & 1.17 & $0.89-1.53$ \\
\hline Unmarried & 1.18 & $0.97-1.43$ & 1.23 & $1.01-1.50$ \\
\hline \multicolumn{5}{|l|}{ Smoking status } \\
\hline Never & Ref. & - & Ref. & - \\
\hline Previous & 1.06 & $0.88-1.30$ & 1.00 & $0.82-1.22$ \\
\hline Current & 1.06 & $0.79-1.43$ & 0.84 & $0.58-1.22$ \\
\hline Depression & 1.85 & $1.52-2.25$ & 0.70 & $0.55-0.89$ \\
\hline \multicolumn{5}{|l|}{ Comorbidity } \\
\hline 0 & Ref. & - & Ref. & - \\
\hline 1 & 1.61 & $1.32-1.96$ & 0.89 & $0.71-1.12$ \\
\hline$>2$ & 1.87 & $1.46-2.41$ & 0.87 & $0.64-1.19$ \\
\hline Asthma & 1.16 & $0.83-1.63$ & 0.75 & $0.49-1.15$ \\
\hline Cognitive impairment & 1.11 & $0.85-1.45$ & 0.82 & $0.52-1.31$ \\
\hline Grip strength, per 10 -unit increase $\mathrm{a}^{\mathrm{a}}$ & 0.83 & $0.74-0.94$ & 1.00 & $0.88-1.14$ \\
\hline \multicolumn{5}{|l|}{ Blocks walked ${ }^{\mathrm{b}}$} \\
\hline$<7$ & 2.14 & $1.72-2.66$ & 0.77 & $0.62-0.96$ \\
\hline $7-27$ & 1.37 & $1.10-1.70$ & 0.87 & $0.69-1.09$ \\
\hline$>28$ & Ref. & - & Ref. & - \\
\hline Hospitalized in the last year & 1.55 & $1.23-1.95$ & 1.03 & $0.77-1.40$ \\
\hline Severity of ADL impairment ${ }^{\mathrm{b}}$ & NA & - & 0.91 & $0.82-1.02$ \\
\hline \multicolumn{5}{|l|}{ Lung function } \\
\hline Normal & Ref. & - & Ref. & - \\
\hline Mild obstruction & 0.71 & $0.46-1.09$ & 1.26 & $0.89-1.77$ \\
\hline Moderate obstruction & 0.90 & $0.70-1.15$ & 1.17 & $0.89-1.52$ \\
\hline Severe obstruction & 0.94 & $0.63-1.38$ & 0.93 & $0.59-1.47$ \\
\hline
\end{tabular}

${ }^{\text {a }}$ For example, comparing a participant with a measured grip strength of $50 \mathrm{~kg}$ to an individual with a measured grip strength of $60 \mathrm{~kg}$. ${ }^{b}$ This refers to the total number of impairments reported during the preceding year.

tion with an interaction term for obstruction and grip strength $(\mathrm{p}=0.29)$ or obstruction and blocks walked $(\mathrm{p}=$ 0.28 ). Both were nonsignificant, indicating that the effect of both was similar for those with and without obstructive lung disease. In a sensitivity analysis excluding patients who reported a physician diagnosis of asthma, we found that the models were similar, with the same factors associated with the development or resolution of IADL or ADL impairment.

In the adjusted models, obstructive lung disease was not associated with the development of ADL impairment (table 5), and did not reduce the likelihood of recovering from ADL impairment. Participants who walked $<7$ blocks were less likely to resolve their ADL impairment (RR 0.77 and 95\% CI 0.62-0.96) than the most physically active subjects.

Disability and Recovery in Airflow Obstruction

\section{Discussion}

In this longitudinal study of older individuals, we found that although participants with moderate to severe obstruction were more likely to have $\geq 1$ IADL impairments at baseline, $31 \%$ of those with moderate obstruction and $22 \%$ with severe obstruction had recovered independent function a year later. While severe obstructive lung disease decreased the likelihood of recovery from IADL impairment, participants with an increased grip strength or who walked more at baseline were more likely to recover, independent of the severity of airflow obstruction.

Our results suggest that the commonly held view that COPD leads to a steadily progressive functional decline with a worsening quality of life and disability over time may not be true for many patients, and that intervening 
early to prevent disability can reduce IADL impairment. We used transition analysis to examine the probability of transitioning between different states of impairment over 1 year. Most studies that have demonstrated a progressive deterioration in functional status use average measures over time $[8,12]$, which does not account for the different patterns of disability that may occur.

We are aware of only 1 study that has looked at patterns of disability in lung disease [17]; lung disease (selfreported asthma or COPD) was associated with 7 different trajectories of disability including 'mild, but decreasing disability' and 'moderately disabled partial regain in functioning after loss'. Our results have built on that study, as we were able to better define the presence and severity of airflow obstruction using spirometry in a population-based longitudinal cohort. In addition, our findings are consistent with prior research in the older general population that suggested that disability is episodic, and that older patients frequently experience a transition between states of disability and independence [15].

Although patients with severe obstruction were less likely to recover independent IADL function, we found that an increase in the number of blocks walked and in muscle strength predicted recovery from IADL impairment regardless of the severity of lung disease. Muscle strength and physical function have been shown to be predictive of development of disability in COPD [31]. In addition, worsening muscle strength and decreased exercise capacity over time are also predictive of new onset of disability measured with the Valued Life Activities Scale [32]. Furthermore, decreased physical activity, measured by self-report [33] or with accelerometry [34], is associated with an increased risk of COPD exacerbations and hospitalizations.

Although decreased physical activity predicts the development of disability, we have also found that increased muscle strength measured by grip strength, and increased physical activity is associated with resolution of IADL impairment, regardless of the severity of obstruction. These findings are consistent with a study by Esteban et al. [35] that found that improved physical activity over a 5-year period is associated with improved health-related quality of life in COPD. These results are in agreement with a study on older patients with a new disability that showed that habitual physical activity shortened the time to recovery and improved the maintenance of independence [16]. Our findings suggest that many patients with chronic obstruction do, in fact, improve, and the factors predicting the resolution of impairment in functioning are similar to older adults without lung disease. Of note, all of the participants in our study were able to walk at baseline and were therefore likely to be able to participate in some physical activity.

The maintenance of physical activity with exercise programs has been shown in randomized trials to slow or prevent functional decline in older persons $[36,37]$. Pulmonary rehabilitation improves the quality of life and exercise tolerance in COPD [38], and may increase the level of physical activity at home as assessed by activity monitors [39]. Bronchodilator therapy [40] and supplemental oxygen [41] may also increase exercise tolerance in COPD. Therefore, optimization of medical therapy and increased access to pulmonary rehabilitation may be ways to improve physical activity and decrease disability that should be examined in future studies of interventions for promoting physical activity in obstructive lung disease. We also found that an increase in grip strength was associated with recovery of independence among persons with obstructive lung disease and disability. Skeletal muscle dysfunction may also contribute to exercise limitation in COPD, and may affect both upper and lower limb skeletal muscle strength [42]. Progressive resistance exercise is often a component of pulmonary rehabilitation, and can increase both arm and leg muscle strength for patients with COPD [43]. Whether an improvement in muscle strength can improve longer-term outcomes and reduce disability is not known.

In this older-population-based cohort, obstructive lung disease was not associated with the development of ADL impairment over 1 year compared to those without lung disease, and did not reduce the likelihood of recovery from ADL impairment. The prevalence of ADL impairment in our study (7\%) was lower than that in a recent cross-sectional survey study, in which $22 \%$ of the older people with self-reported COPD (age 60-79 years) had ADL impairment [44]. Our study was different in that all patients were ambulatory at baseline, we were able to confirm the diagnosis of airflow obstruction with spirometry, and we were able to examine whether obstruction predicted the development or resolution of impairment over a period of 1 year.

The reason airflow obstruction is associated with impairment in IADLs, but not in ADLs, may be because IADLs, e.g. heavy housework, are more likely to be impaired by lung disease. For example, ADL impairment such as difficulty with eating, getting out of bed or walking around the house reflects much more severe impairment, so that even severe obstruction, in most cases, may not result in this degree of impairment and other chronic conditions such as dementia rather play a role. 
Several limitations of this study should be considered. The participants did not receive postbronchodilator spirometry, and so we may have included individuals with poorly controlled asthma. However, excluding participants who reported a physician diagnosis of asthma did not change the results of the analysis for predicting the development or resolution of disability. In addition, although we controlled for chronic illnesses that may contribute to disability, diagnoses such as visual or hearing impairments were not measured in CHS and may also have contributed to IADL or ADL impairment. The CHS only included participants $\geq 65$ years, thus limiting the generalizability of the results. We were unable to assess how many subjects were participating in a pulmonary rehabilitation program; however, such participation is generally low [45]. In addition, when this study was conducted, pulmonary rehabilitation was not yet covered by Medicare [46]. We imputed a small proportion of missing values for yearly IADL, depression, prior hospitalization within the last year, cognitive status and blocks walked which may have affected our results.

\section{Conclusions}

In conclusion, older people with obstructive lung disease often experience periods of disability, but often a transition from a state of disability to independent functioning. This suggests that for many patients with obstructive lung disease, disability is not steadily progressive, but episodic. Regardless of the presence or absence of airflow obstruction, those who remain physically active and have increased muscle strength are more likely to recover from IADL impairment over a 1 -year period. Pulmonary rehabilitation may be an approach to improve exercise tolerance and muscle strength among individu- als with airflow obstruction. Future research is needed to determine whether interventions to increase physical activity and muscle strength can help patients with IADL impairment to recover independent function.

\section{Acknowledgements}

The research reported in this article was supported by contracts HHSN268201200036C, N01-HC-85239, N01-HC-85079 through N01-HC-85086, N01-HC-35129, N01 HC-15103, N01 HC-55222, N01-HC-75150, N01-HC-45133 and grant HL080295 from the National Heart, Lung, and Blood Institute, with additional contributions from the National Institute of Neurological Disorders and Stroke. Support was also provided through AG-023629, AG15928, AG-20098 and AG-027058 from the National Institute on Aging. A full list of principal CHS investigators and institutions can be found at http://www.chs-nhlbi.org/pi.htm.

\section{Financial Disclosure and Conflicts of Interest}

Dr. Avdalovic received research support from Merck, GlaxoSmith Kline and Novartis. Dr. Barr received grants or contracts from the National Institutes of Health (NIH; US-EPA) and the Alpha1 Foundation; in-kind contribution from Cenestra Health, travel reimbursement from Boeringher Ingleheim and royalties from UpToDate. Dr. Fan received grants from the NIH and Department of Veterans Affairs (VA) and has served as a consultant to Uptake Medical. Dr. Krishnan received grants from the NIH and PCORI and royalties from UpToDate. No other authors have any financial interests to report, and none of the authors report any conflicts of interest with the material in the manuscript. The views expressed in this article are those of the authors and do not necessarily reflect the position or policy of the Department of VA or the United States government. This material is the result of work supported by resources from the VA Puget Sound Health Care System, Seattle, Washington, USA.

\section{References}

1 Mathers CD, Fat DM, Boerma JT: The Global Burden of Disease: 2004 Update. Geneva, World Health Organization, 2008.

-2 Iglehart JK: Prioritizing comparative-effectiveness research - IOM recommendations. $\mathrm{N}$ Engl J Med 2009;361:325-328.

-3 Coultas DB, Mapel D, Gagnon R, Lydick E: The health impact of undiagnosed airflow obstruction in a national sample of United States adults. Am J Respir Crit Care Med 2001;164:372-377.

-4 Graydon JE, Ross E, Webster PM, Goldstein RS, Avendano M: Predictors of functioning of patients with chronic obstructive pulmonary disease. Heart Lung 1995;24:369-375.
5 Lee RN, Graydon JE, Ross E: Effects of psychological well-being, physical status, and social support on oxygen-dependent COPD patients' level of functioning. Res Nurs Health 1991;14:323-328.

6 6 Tinetti ME, McAvay G, Chang SS, Ning Y, Newman AB, Fitzpatrick A, Fried TR, Harris TB, Nevitt MC, Satterfield S, Yaffe K, Peduzzi $P$ : Effect of chronic disease-related symptoms and impairments on universal health outcomes in older adults. J Am Geriatr Soc 2011; 59:1618-1627.
7 Locke E, Thielke S, Diehr P, Wilsdon AG, Graham Barr R, Hansel N, Kapur VK, Krishnan J, Enright P, Heckbert SR, Kronmal RA, Fan VS: Effects of respiratory and non-respiratory factors on disability among older adults with airway obstruction: the Cardiovascular Health Study. COPD 2013;10:588596.

-8 Oga T, Nishimura K, Tsukino M, Sato S, Hajiro T, Mishima M: Longitudinal deteriorations in patient reported outcomes in patients with COPD. Respir Med 2007;101:146-153. 
-9 Spencer S, Calverley PM, Sherwood Burge P, Jones PW: Health status deterioration in patients with chronic obstructive pulmonary disease. Am J Respir Crit Care Med 2001;163: 122-128.

10 Jones PW, Anderson JA, Calverley PM, Celli BR, Ferguson GT, Jenkins C, Yates JC, Vestbo J, Spencer MD: Health status in the torch study of COPD: treatment efficacy and other determinants of change. Respir Res 2011;12: 71.

-11 Calverley P, Pauwels R, Vestbo J, Jones P, Pride N, Gulsvik A, Anderson J, Maden C: Combined salmeterol and fluticasone in the treatment of chronic obstructive pulmonary disease: a randomised controlled trial. Lancet 2003;361:449-456.

12 Kapella MC, Larson JL, Covey MK, Alex CG: Functional performance in chronic obstructive pulmonary disease declines with time. Med Sci Sports Exerc 2011;43:218-224.

13 Cooper CB: Airflow obstruction and exercise. Respir Med 2009;103:325-334.

14 Halpin DM, Miravitlles M: Chronic obstructive pulmonary disease: the disease and its burden to society. Proc Am Thorac Soc 2006; 3:619-623.

15 Hardy SE, Dubin JA, Holford TR, Gill TM: Transitions between states of disability and independence among older persons. Am J Epidemiol 2005; 161:575-584.

$\checkmark 16$ Hardy SE, Gill TM: Factors associated with recovery of independence among newly disabled older persons. Arch Intern Med 2005 165:106-112.

-17 Nusselder WJ, Looman CW, Mackenbach JP: The level and time course of disability: trajectories of disability in adults and young elderly. Disabil Rehabil 2006;28:1015-1026.

$\checkmark 18$ Fried LP, Borhani NO, Enright P, Furberg CD, Gardin JM, Kronmal RA, Kuller LH, Manolio TA, Mittelmark MB, Newman A, et al: The Cardiovascular Health Study: design and rationale. Ann Epidemiol 1991;1:263276.

19 Jiang R, Burke GL, Enright PL, Newman AB, Margolis HG, Cushman M, Tracy RP, Wang Y, Kronmal RA, Barr RG: Inflammatory markers and longitudinal lung function decline in the elderly. Am J Epidemiol 2008; 168 : 602-610.

20 Hankinson JL, Odencrantz JR, Fedan KB: Spirometric reference values from a sample of the general US population. Am J Respir Crit Care Med 1999;159:179-187.

21 Mannino DM, Ford ES, Redd SC: Obstructive and restrictive lung disease and functional limitation: data from the Third National Health and Nutrition Examination. J Intern Med 2003;254:540-547.

22 Hyatt RE, Cowl CT, Bjoraker JA, Scanlon PD: Conditions associated with an abnormal nonspecific pattern of pulmonary function tests. Chest 2009;135:419-424.
3 Iyer VN, Schroeder DR, Parker KO, Hyatt RE, Scanlon PD: The nonspecific pulmonary function test: longitudinal follow-up and outcomes. Chest 2011;139:878-886.

24 Charlson ME, Pompei P, Ales KL, MacKenzie CR: A new method of classifying prognostic comorbidity in longitudinal studies: development and validation. J Chronic Dis 1987;40: 373-383.

25 Andresen EM, Malmgren JA, Carter WB, Patrick DL: Screening for depression in well older adults: evaluation of a short form of the CES-D (Center for Epidemiologic Studies Depression Scale). Am J Prev Med 1994;10: 77-84.

26 Kurella M, Chertow GM, Fried LF, Cummings SR, Harris T, Simonsick E, Satterfield S, Ayonayon H, Yaffe K: Chronic kidney disease and cognitive impairment in the elderly: the Health, Aging, and Body Composition Study. J Am Soc Nephrol 2005;16:2127-2133.

27 Ferris BG: Epidemiology standardization project (American Thoracic Society). Am Rev Respir Dis 1978;118:1-120.

28 Diehr P, Thielke S, O’Meara E, Fitzpatrick AL, Newman A: Comparing years of healthy life, measured in 16 ways, for normal weight and overweight older adults. J Obes 2012;2012: 894894.

29 Diehr P, Yanez D, Derleth A, Newman AB: Age-specific prevalence and years of healthy life in a system with three health states. Stat Med 2008;27:1371-1386.

30 Zou G: A modified Poisson regression approach to prospective studies with binary data. Am J Epidemiol 2004;159:702-706.

- 31 Eisner MD, Iribarren C, Blanc PD, Yelin EH, Ackerson L, Byl N, Omachi TA, Sidney S, Katz PP: Development of disability in chronic obstructive pulmonary disease: beyond lung function. Thorax 2011;66:108-114.

32 Singer JP, Katz PP, Iribarren C, Omachi TA, Sanchez G, Yelin EH, Cisternas MG, Blanc PD: Both pulmonary and extra-pulmonary factors predict the development of disability in chronic obstructive pulmonary disease. Respiration 2013;85:375-383.

33 Benzo R, Chang CC, Farrell MH, Kaplan R, Ries A, Martinez FJ, Wise R, Make B, Sciurba F: Physical activity, health status and risk of hospitalization in patients with severe chronic obstructive pulmonary disease. Respiration 2010;80:10-18.

34 Moy ML, Teylan M, Weston NA, Gagnon DR, Garshick E: Daily step count predicts acute exacerbations in a US cohort with COPD. PLoS One 2013;8:e60400.
5 Esteban C, Quintana JM, Aburto M, Moraza J, Egurrola M, Perez-Izquierdo J, Aizpiri S, Urko A, Capelastegui A: Impact of changes in physical activity on health-related quality of life among patients with chronic obstructive pulmonary disease. Eur Respir J 2010;36:292300.

36 Gill TM, Baker DI, Gottschalk M, Peduzzi PN Allore $\mathrm{H}$, Byers A: A program to prevent functional decline in physically frail, elderly persons who live at home. N Engl J Med 2002; 347:1068-1074.

37 Binder EF, Schechtman KB, Ehsani AA, Steger-May K, Brown M, Sinacore DR, Yarasheski KE, Holloszy JO: Effects of exercise training on frailty in community-dwelling older adults: results of a randomized, controlled trial. J Am Geriatr Soc 2002;50:1921-1928.

- 38 Lacasse Y, Goldstein R, Lasserson TJ, Martin S: Pulmonary rehabilitation for chronic obstructive pulmonary disease. Cochrane Database Syst Rev 2006;CD003793.

39 Casaburi R: Activity promotion: a paradigm shift for chronic obstructive pulmonary disease therapeutics. Proc Am Thorac Soc 2011; 8:334-337

40 Aguilaniu B: Impact of bronchodilator therapy on exercise tolerance in COPD. Int J Chron Obstruct Pulmon Dis 2010;5:57-71.

41 Bradley JM, Lasserson T, Elborn S, Macmahon J, O'Neill B: A systematic review of randomized controlled trials examining the short-term benefit of ambulatory oxygen in COPD. Chest 2007;131:278-285.

42 Nici L, Donner C, Wouters E, Zuwallack R, Ambrosino N, Bourbeau J, Carone M, Celli B, Engelen M, Fahy B, Garvey C, Goldstein R, Gosselink R, Lareau S, MacIntyre N, Maltais F, Morgan M, O'Donnell D, Prefault C, Reardon J, Rochester C, Schols A, Singh S, Troosters T: American Thoracic Society/European Respiratory Society Statement on Pulmonary Rehabilitation. Am J Respir Crit Care Med 2006;173:1390-1413.

43 O'Shea SD, Taylor NF, Paratz JD: Progressive resistance exercise improves muscle strength and may improve elements of performance of daily activities for people with COPD: a systematic review. Chest 2009;136:1269-1283.

44 Rodriguez-Rodriguez P, Jimenez-Garcia R, Hernandez-Barrera V, Carrasco-Garrido P, Puente-Maestu L, de Miguel-Diez J: Prevalence of physical disability in patients with chronic obstructive pulmonary disease and associated risk factors. COPD 2013;10:611617.

45 Johnston K, Grimmer-Somers K: Pulmonary rehabilitation: overwhelming evidence but lost in translation? Physiother Can 2010;62: 368-373.

46 Birnbaum S: Pulmonary rehabilitation: a classic tune with a new beat, but is anyone listening? Chest 2011;139:1498-1502. 